\title{
Fault Characterisation of a DC Microgrid with Multiple Earthing under Grid Connected and Islanded Operations
}

\author{
Ahmad Makkieh, Abdullah Emhemed, \\ Dong Wang, Graeme Burt, Scott Strachan \\ Institute for Energy and Environment, University of Strathclyde, \\ Glasgow, UK, ahmad.makkieh@strath.ac.uk
}

\begin{abstract}
Direct Current (DC) microgrids are gaining an international interest to improve the flexibility and the reliability of future distribution systems. DC microgrids are more suitable and efficient infrastructure for connecting and controlling distributed energy resources. However, they do present new challenges under different fault conditions. To design appropriate protection solutions to handle such challenges and ensure DC microgrid secure operation under different operation modes (grid-connected and islanded), there is a need to fully understand their fault behaviour under each DC microgrid mode. Therefore, this paper investigates in detail the fault behaviours associated with DC microgrids with local distributed energy resources under different fault conditions (e.g. DC pole to ground and pole to pole faults). A DC microgrid modelled in PSCAD/EMTDC with the appropriate layout, multiple earthing and control structures is used as a test network in the simulation fault studies.
\end{abstract}

Keywords - DC microgrid, Distributed resources, Distribution network, Fault analysis, DC protection

\section{INTRODUCTION}

Recently Direct Current (DC) microgrids have attracted international interest and considered as a promising new paradigm for providing an enhanced controllability of local distribution systems. This is in addition to their capability for increasing electrification in remote areas in developing countries, and grid improvement in developed nations [1-2]. Several applications such as data centres, information communication systems and electric ships have already been implemented DC microgrids. The control and performance of the DC microgrid should be operated in either connected or islanded from the grid [3]. Relatively, most work in literature and even existing trials of DC distribution have considered conventional converters such as two level voltage source converters (VSCs) as the way to interface AC and DC [4]. In addition, many power electronic converters are integrated in the DC microgrid such as buck converters and buck-boost converters. These have the issue that they cannot block the fault current when a DC fault occurs. Despite this, much research has focused on the design of current controllers and operational strategies that enable converters to switch between grid-tied and islanded modes [3-4], with little known about the impacts of the transition between these two modes under faulted conditions, which will become more challenging when DC microgrid operates islanded from the grid. The fault current could potentially be undetectable

\author{
Adria Junyent-Ferre \\ Imperial College London, UK
}

to traditional protection devices, leading to non-detection of circuit faults and significant risk of protection mal-operation. These challenges in addition to the converter sensitivity to faults and selecting an optimal earthing scheme make the protection coordination and selectivity difficult. Consequently, a full understanding of the fault behaviour and characteristics under each DC microgrid operating mode is required. The main contribution of this paper is to conduct an investigation into the fault behaviour associated with DC microgrids whilst keeping the earthing tethered to the negative pole. Furthermore, a transient simulation for different faults conditions in a DC microgrid network is performed in order to examine the fault behaviour under different operation modes. The paper is organised as follows. Section II presents the fault characteristics of different converter configurations in DC microgrid. A simplified DC microgrid model is demonstrated in Section III. In Section IV the simulation analysis is presented. Finally, the discussion of the results and conclusion of the presented work are drawn in section V and VI.

\section{FAULT CHARACTERISTICS OF DIFFERENT CONVERTER CONFIGURATIONS IN DC MICROGRID}

Two types of fault can occur on the DC side: first an internal DC fault where the fault occurs inside the main converter and second an external DC fault where the fault arises on the converter terminals or at the remote locations on downstream DC network. There are a number of converter topologies that have been utilized in existing DC microgrid projects such as VSCs and neutral point clamped (NPC) converters [7]. These two converters under faulted condition will provide a significant transient and steady state fault currents. Comparatively, modular multilevel converters (MMCs) which have the potential to be used for future DC microgrid systems have more power fault management capabilities and resilient operation[8]. The half bridge MMC can only limit the fault current transient, whereas, the full bridge MMC can block the DC fault current completely [9]. Regarding to the DC-DC buck-boost converters, the half bridge DC-DC converters lack fault current management capabilities. In this paper, two-level VSC and DC/DC buckboost converters are selected for this study as they are widely used in DC microgrid systems. More details about the behaviours of these converters under faulted conditions are introduced in the sub-section. 


\section{A. Two-level voltage source converter}

A number of stages occur when a short circuit fault occurs in a two-level VSC. During the first stage the capacitor discharges (natural response). The second stage is the diode freewheel which provides paths for the fault currents feeding from the line conductors and the AC grid. This stage is the most challenging for the diodes, which must have enough rating to tolerate such currents. The last stage when the grid side current contribution feeding to the fault location. More details of mathematical expression related to these stages and behaviours can be found in [9][10].

\section{B. DC/DC Buck-Boost converter}

In the case of a buck-boost converter, at the first submillisecond after the fault initiation, the converter remains operational until it is blocked due to the over-current. All IGBTs valves are blocked meaning that the converter will work as a bridge converter. This is depending on the fault location. Only the fault current in the buck direction can be blocked, whilst the filter capacitor is free to discharge during the faults. More details related to the behaviours of buckboost converter can be found in [11].

\section{DC MCROGRID TEST SYSTEM DESCRIPTION}

The test network is based on a typical microgrid DC network, which has been adopted from [11] and modelled in PSCAD/EMTDC. The DC network shown in Fig. 1 is connected to an AC secondary substation of $11 / 0.4 \mathrm{kV}$ transformer by a two-level VSC. A battery energy storage system (BESS) is connected to the DC point of common coupling (PCC), and has been set to maintain a $750 \mathrm{Vdc}$ voltage at the PCC to enable stable operation of the DC microgrid in both grid-connected and islanded operation modes [12]. A DC-DC converter as illustrated in Fig. 1 is used to step down the DC voltage to $400 \mathrm{~V}$ on the end-user side. A lumped DC load equivalent to $500 \mathrm{~kW}, 10 \mathrm{~kW}$ PV and $7.8 \mathrm{kWh}$ battery storage are connected to the DC end-user bus. A multiple point earthing of a capacitor in parallel with a diode are used for ground fault detection and personal safety. Fig. 2 manifests the equivalent circuit of $\mathrm{DC}$ microgrid with multiple earthing points under DC P-P fault condition. The DC microgrid test system parameters are illustrated in Table 1.

Table 1 DC Microgrid Test system parameter [11]

\begin{tabular}{cc}
\hline \hline Parameter & Value \\
\hline AC supply & $11 \mathrm{kV}$ \\
Transformer X/R & 5 \\
Fault level & $156 \mathrm{MVA}$ \\
Transformer capacity & $1 \mathrm{MVA}$ \\
Choke Inductance $[$ LChoke $]$ & $0.003 \mathrm{H}$ \\
DC-Link Capacitance[Cdc] & $3300 \mu \mathrm{F}$ \\
LVDC main voltage & $750 \mathrm{~V}$ (pole-to-pole) \\
R and L of LVDC cable & $0.164 \Omega / \mathrm{km}, 0.24 \mathrm{mH} / \mathrm{km}$ \\
Cable length & $1 \mathrm{~km}$ \\
PV generation & $10 \mathrm{~kW}$ \\
Battery system & $7.8 \mathrm{kWh}$ \\
DC loads & $500 \mathrm{~kW}$ \\
\hline \hline
\end{tabular}

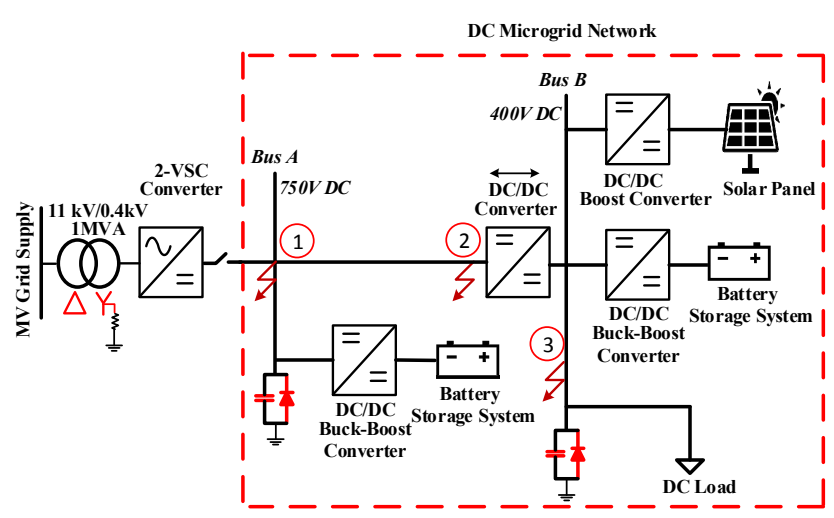

Fig. 1 DC microgrid test network



Fig. 2 Equivalent circuit of DC microgrid network under pole-to-pole fault

\section{A. Model of Two-Level VSC}

The two-level voltage source converter that interfaces the DC microgrid to the AC grid is modelled as a detailed twolevel VSC. The converter is controlled using space vector pulse width modulation (SV-PWM) technique. Two controllers, known as outer control and inner control loop are employed in the two-level VSC as shown in Fig. 3. The outer control loop generates a three-phase voltage reference signal based on the mode of the VSC operation (e.g. voltage or power control mode). The inner control loop controls the switching of the power electronics (e.g. IGBTs), since the SV-PWM technique is adopted. Such converter is equipped with a DC capacitor whose main purpose is to maintain a constant DC side voltage $\left(v_{d c}\right)$. An inductance is connected in series with the AC terminal to sustain the AC side current constant in the short period between switching.

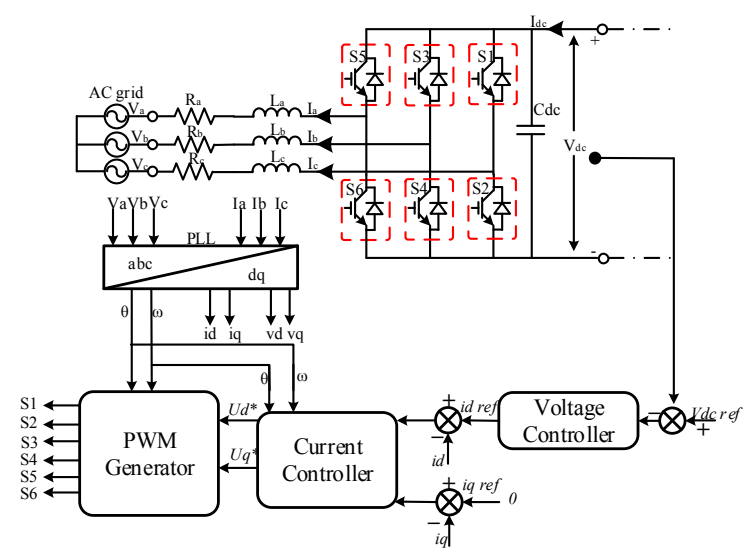

Fig. 3 Diagram two-level voltage source converter with control loops 


\section{B. Model of DC/DC Bidirectional converter}

The bidirectional DC/DC converter is used to connect the supply network to the DC customer side. The voltage-mode control technique is used to maintain the output dc voltage at a desired value with a feedback loop. The DC voltage is measured and compared to the reference signal $\left(V_{\text {ref }}\right)$. The error signal is generated and delivered to a proportionalIntegral $(P I)$ controller. The output of the PI controller is pulse width modulated to generate gating pulses for the power electronics valves (e.g. IGBTs).

\section{Model of PV with DC/DC Boost Converter}

The PV array of $10 \mathrm{~kW}$ is modelled according to the equations in [13], and connected to a boost converter as shown in Fig. 4, that uses a maximum power point tracking (MPPT) algorithm to extract maximum power from the PV. The simulation parameters are established in Table 2.

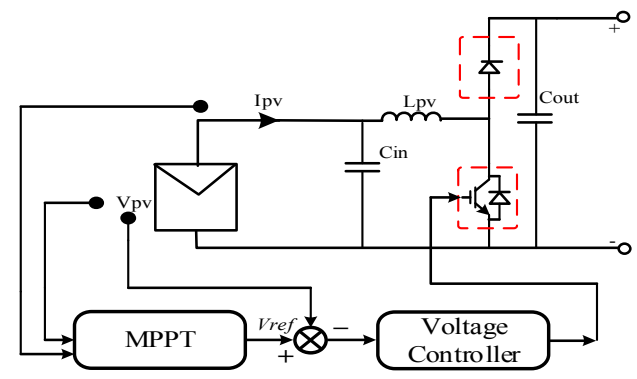

Fig. 4 Diagram of PV with MPPT based DC/DC Boost converter

Table 2 PV array and Boost converter simulation parameters[11]

\begin{tabular}{cccccc}
\hline Isc & Vmppt & Pmax & Cin & Cout & Lpv \\
\hline \hline $83 \mathrm{~A}$ & $135 \mathrm{~V}$ & $10 \mathrm{~kW}$ & $270 \mu \mathrm{F}$ & $1000 \mu \mathrm{F}$ & $0.001 \mathrm{H}$ \\
\hline
\end{tabular}

D. Model of BESS with DC/DC Buck-Boost Converter

A $7.8 \mathrm{kWh}$ battery energy storage system is connected to the bidirectional dc/dc buck-boost converter as shown in Fig. 5 , which is used to control the operation mode of BESS. It operates as a boost converter in discharging mode and as a buck converter in the charging mode. The simulation parameters are established in Table 3.

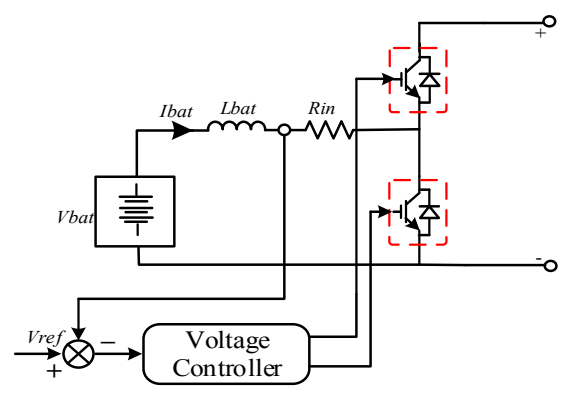

Fig. 5 Diagram of BESS with DC/DC Buck- Boost converter

Table 3 BESS and Buck-Boost converter simulation parameters[11]

\begin{tabular}{cccc}
\hline Icharge & Vbat & Rin & Lbat \\
\hline \hline $13 \mathrm{~A}$ & $140 \mathrm{~V}$ & $0.05 \Omega$ & $0.001 \mathrm{H}$ \\
\hline
\end{tabular}

\section{SIMULATION STUDIES}

This section investigates through simulation studies different fault behaviours of the test DC microgrid network under AC grid connected and islanded operation modes. Two different extreme fault conditions: DC pole-to-pole (L-L) fault and DC pole-to-earth (L-G) fault were applied at different locations (shown as location 1-3 in Fig. 1). Each fault is initiated at time $t=1.5 \mathrm{~s}$ with fault resistance $\left(R_{f}\right)$ of $0.01 \Omega$, while no protection actions are implemented. The response in each case is discussed as follows.

\section{A. Case 1: DC Micorgrid connected to AC grid}

\section{1) DC pole-to-pole fault}

Fault applied at location 1: when a pole-to-pole fault is applied at bus A as shown in Fig. 1, high transient currents occur due to the discharge of the VSC smoothing capacitor, the BESS DC-DC converter capacitor, and the end-user DCDC converter capacitor shown as $C_{v s c}, C_{B E S S}$, and $C_{D C}$ in Fig. 2 respectively. The peak value of the total transient fault current in this case as shown in Fig. 6(a) has reached 20kA. This is followed by a steady state fault current equal to $1.35 \mathrm{kA}$. Fig. 6(b) presents the fault profile in the earth path. When the fault is initiated, a closed fault loop through the earthing diode (shown as $D_{l}$ in Fig. 2) is created between the two earthing points presented as $E_{1}$ and $E_{2}$ in Fig. 2. Diode $D_{2}$ that is connected across the earthing capacitor $C_{2}$ remains an open circuit. This has led to a circulation of a transient current with a $1.2 \mathrm{kA}$ peak between the $C_{l}$ and $D_{l}$, and decays within less than $5 \mathrm{~ms}$ as illustrated by IC1-L1 in Fig. 6(b). The discharge from $C_{2}$ will be limited by impedance of the line between $E_{1}$ and $E_{2}$.

Fault applied at location 2: in this case the transient fault current peak of the upstream current reaches $2 \mathrm{kA}$ as shown in Fig. 6(c). At this fault location and in contrast to location 1, the diode $D_{2}$ (see Fig. 2) provides the earth loop path between the two earthing points $E_{1}$ and $E_{2}$, and the diode $D_{1}$ remains open. The capacitor $C_{2}$ has circulated a transient current with $1.8 \mathrm{kA}$ as shown in Fig. 6(b), and the earthing capacitor $C_{1}$ has relatively limited discharge due to the equivalent cable impedance between $E_{1}$ and $E_{2}$ points.

Fault applied at location 3: when the fault is applied at bus B (see Fig. 1), the main current contributions to the fault are supplied locally from the PV and the BESS since their converters are unable to limit the fault current in the boost direction as discussed in section II

2) DC pole- to- earth fault

Fault applied at location 1: when a pole (L+)-to-earth fault is applied at this location, the transient discharge currents by the associated capacitors $\left(C_{v S c}, C_{B E S S}\right.$, and $\left.C_{D C}\right)$ are very similar to pole-to-pole faults as presented previously in Fig. 6(a). Diodes $D_{1}$ and $D_{2}$ of the earth points $E_{1}$ and $E_{2}$ are forward biased and create a closed earth path, resulting in the discharge of the earthing capacitor $C_{1}$ with transient current with a peak of $0.35 \mathrm{kA}$ and $C_{2}$ with a peak of $0.14 \mathrm{kA}$ as shown in Fig. 7(a). Both earthing capacitors are shorted when the fault is initiated, but their transient circulation currents are different. This is due to the differences in their pre-fault voltages as they are located at different locations in the microgrid. 
Fault applied at location 2: in this case the fault current transients are governed by the discharging capacitors of the upstream side (main VSC and BESS connected to the Bus A) with a $2 \mathrm{kA}$ peak current and the downstream DC-DC converters with $0.5 \mathrm{kA}$ peak current as illustrated in Fig. 7(b). The earth fault current path is created by both diodes $D_{l}$ and $D_{2}$, and the fault current response of the associated earthing capacitors are presented in Fig. 7 (a).

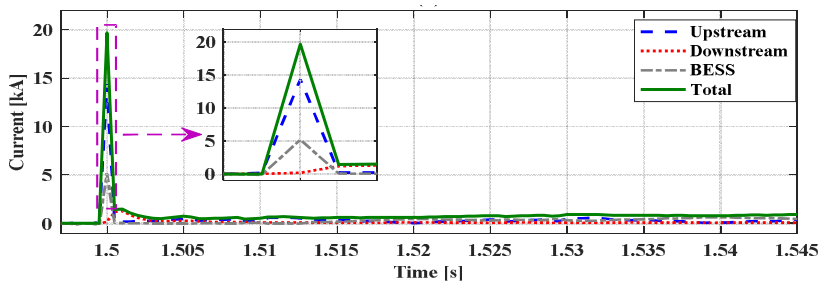

(a)



(b)

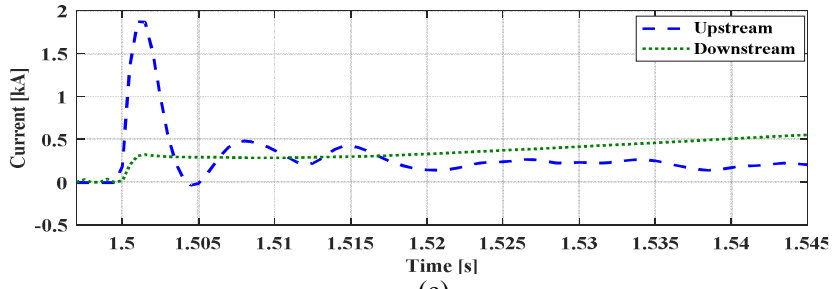

(c)

Fig. 6 Pole-to-pole fault response at location $1 \& 2$ (a) upstream and downstream fault profiles (b) current profiles of the earthing capacitors $\mathrm{C} 1$ and $\mathrm{C} 2$ (c) upstream and downstream current responses for location 2

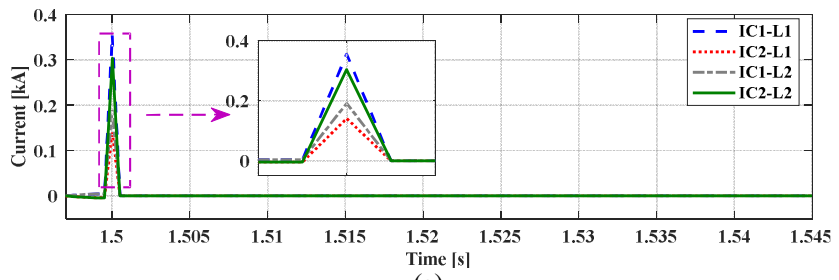

(a)

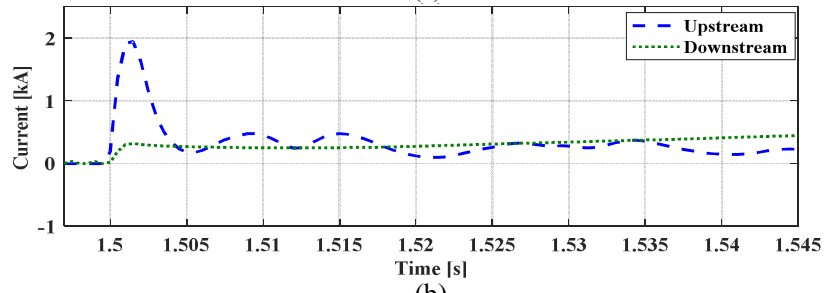

(b)

Fig. 7 Pole-to-earth fault response at location $1 \& 2$, (a) current profiles of the earthing capacitors $\mathrm{C} 1$ and $\mathrm{C} 2$ (b) upstream and downstream current responses for location 2

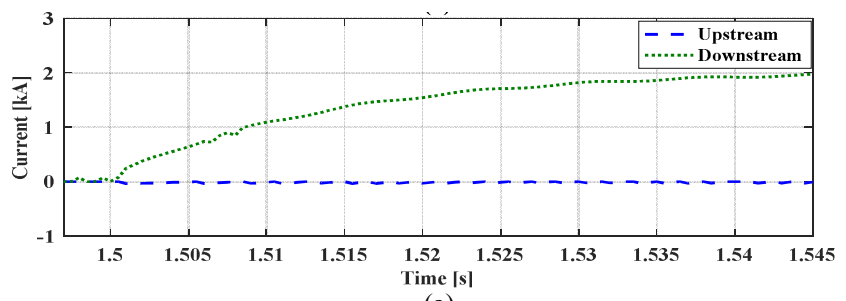

(a)

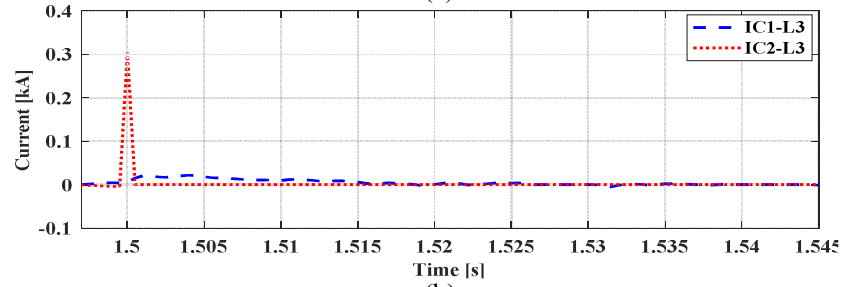

(b)

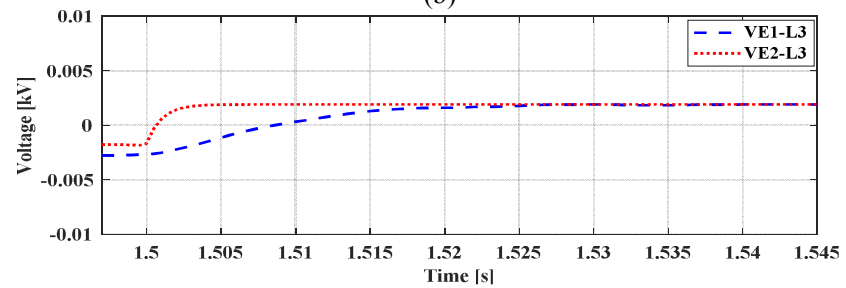

(c)

Fig. 8 Pole-to-earth fault response at location 3, (a)upstream and downstream fault profiles (b) current profiles of the earthing capacitors $\mathrm{C} 1$ and C2 (c) Transient voltage across earthing point of E1 and E2.

Fault applied at location 3: when a pole ( $\mathrm{L}+$ )-to-earth fault is applied on the DC customer side, the main contribution to the fault current is from downstream and no current flows from upstream as shown in Fig. 8(a). The upstream fault current is blocked by the DC/DC converter in respect to the fault location 3 , whilst the earthing capacitor $C_{2}$ discharges a transient fault current with $0.3 \mathrm{kA}$ peak as shown in Fig. 8(b). The transient voltages across each earthing capacitor $\left(C_{I}\right.$ and $\left.C_{2}\right)$ are given in Fig. 8(c).

\section{B. Case 2: DC Microgrid in an Islanded mode}

\section{1) DC pole-to-pole fault}

Fault applied at location 1: in this case, the main twolevel VSC interfacing the AC grid is disconnected. Only the BESS's filter capacitor $\left(C_{B E S S}\right)$ and the downstream DC-DC converter's capacitor $\left(C_{D C}\right)$ supply a transient current with a 6kA peak as shown in Fig. 9(a). As for the steady state fault current, the majority of the current $(1.1 \mathrm{kA})$ is supplied by the BESS connected to Bus A.

The fault response of the earthing capacitors connected to the earthing points $E_{1}$ and $E_{2}$ are similar to the previous poleto-pole fault in case 1 (the microgrid $\mathrm{AC}$ grid-connected mode, see Fig. 6(b)). The transient discharging currents of the earthing capacitors $C_{1}$ and $C_{2}$ are presented in Fig. 9(b) as $I C 1-L 1$ and $I C 2-L 1$ respectively.

Fault applied at location 2: when a pole-to-pole fault occurs at this location, the peak transient fault currents discharged by $C_{B E S S}$ and the $C_{D C}$ are found to be $1.2 \mathrm{kA}$ and $0.3 \mathrm{kA}$ respectively, as illustrated in Fig. 9(c). Whereas, the discharge transient currents of the earthing capacitors $C_{l}$ and $C_{2}$ are presented as ICI-L2 and IC2-L2 in Fig. 9(b), and the 
transient voltages across each earthing capacitor are shown in Fig. 9(d).

Fault applied at location 3: when the fault is applied at bus B (see Fig. 1), the main current contributions to the fault are supplied locally from the PV and the BESS which are very similar to pole-to-pole faults under connected mode as presented previously in Fig. 6(a)

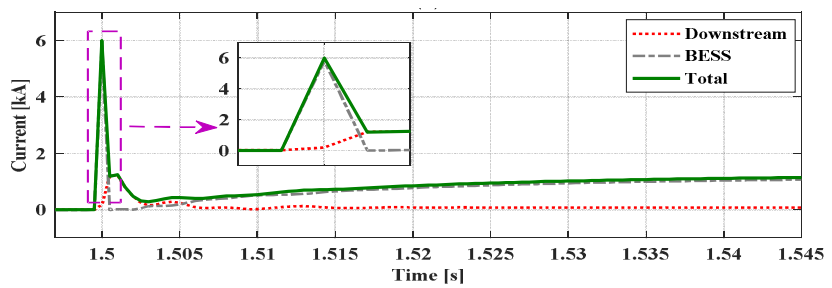

(a)

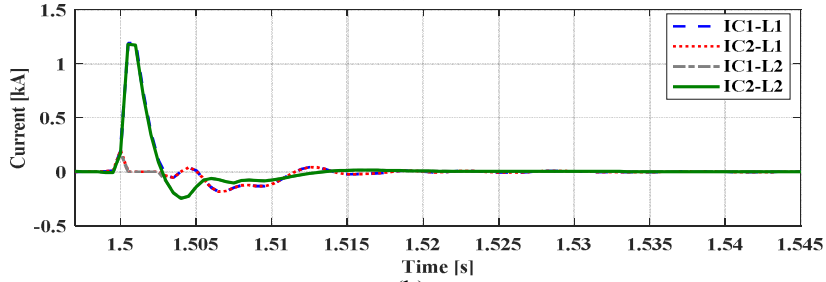

(b)

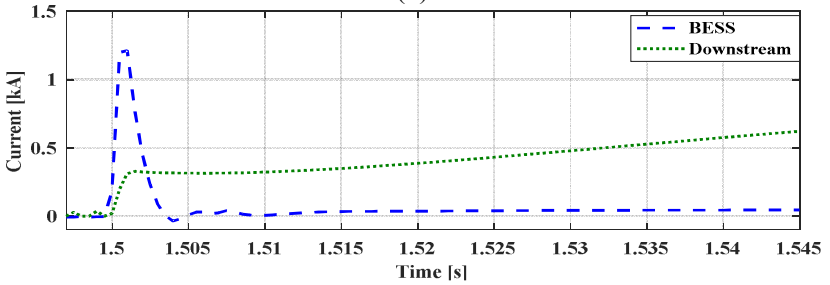

(c)

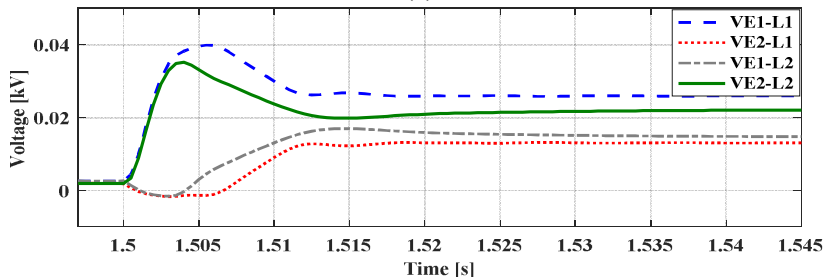

(d)

Fig. 9 Pole-to-pole fault response at location $1 \& 2$, (a)downstream and BESS fault profiles (b) current profiles of the earthing capacitors $\mathrm{C} 1$ and C2 (c) BESS and downstream current responses for location 2 (d) Transient voltage across earthing point of E1 and E2.

\section{1) DC pole-to-earth fault}

Fault applied at location 1: a pole $\mathrm{L}+$-to-earth fault is applied, and it has been found that BESS filter capacitor $\left(C_{B E S S}\right)$ and the downstream DC-DC converter's capacitor $\left(C_{D C}\right)$ have discharged almost the same currents as in poleto-pole fault that is presented in Fig. 9(a) (with 6kA peak current). The steady state fault current provided by the BESS and downstream sources are also almost similar to pole-topole fault shown in Fig. 9(a). However, the behaviour of the earthing capacitors $C_{1}$ and $C_{2}$ is significantly different from the pole-to-pole fault case. The diode $D_{l}$ connected to the earthing point $E_{l}$ is creating the earth path between the earthing points $E_{1}$ and $E_{2}$, and allows the earthing capacitor $C_{1}$ to circulate transient current with $0.48 \mathrm{kA}$ peak as shown as ICI-LI in Fig. 10(a). The diode $D_{2}$ connected to the earthing point E2 conducts, and this makes $C_{2}$ to discharge lower fault current $(0.2 \mathrm{kA})$ as presented by $I C 2-L 1$ in Fig. 10(a) due to the equivalent fault impedance within the earth path. The $C_{1}$ and the $C_{2}$ transient currents are almost half of compared to the pole-to-pole case.

Fault applied at location 2: in this case the fault current transient is coming from discharging the capacitor of BESS $\left(C_{B E S S}\right)$ and the capacitor of the end-user DC-DC converter capacitor $\left(C_{D C}\right)$ resulting to high current transients with 1.2 $\mathrm{kA}$ and $0.5 \mathrm{kA}$ respectively as shown in Fig. $10(\mathrm{~b})$. Diode $D_{2}$ connected to the earthing point E2 is creating the earth path between the earthing points $E_{1}$ and $E_{2}$, and allows the earthing capacitor $C_{2}$ to circulate transient current with $0.4 \mathrm{kA}$ peak as shown as $I C 2-L 2$ in Fig. 10(a). The diode $D_{l}$ connected to the earthing point $E_{l}$ conducts and makes $C_{l}$ to discharge a lower fault current $(0.2 \mathrm{kA})$ as presented by $I C 1$ L2 in Fig. 10(a)

Fault applied at location 3: when a pole-to-earth fault is applied at the end-user Bus B (see Fig. 1), only downstream current contributions from the PV and local BESS experience a high transient current with a total peak of $2 \mathrm{kA}$ as illustrated in Fig. 11(a). The diode $D_{2}$ connected to the earthing point $E_{2}$ is creating the earth path, and allows the earthing capacitor $C_{2}$ to circulate transient current with $0.4 \mathrm{kA}$ peak as shown as IC1-L3 in Fig. 11(b). Diode $D_{l}$ connected to the earthing point $E_{l}$ does not conduct and $C_{l}$ does not discharge as presented by IC1-L3 in Fig. 11(b).

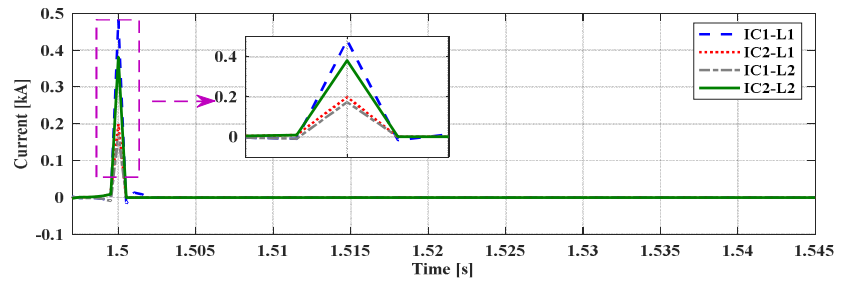

(a)



(b)

Fig. 10 Pole-to-earth fault response at location $1 \& 2$, (a) current profiles of the earthing capacitors $\mathrm{C} 1$ and $\mathrm{C} 2$ (b) BESS and downstream current responses for location 2

\section{DISCUSSION OF SIMULATION RESULTS}

The simulation results show that the pole-to-pole (P-to-P) faults at location 1 and 2 make the entire $\mathrm{DC}$ microgrid to encounter extensive voltage drop and high DC current transients. In this case, the upstream and downstream converters cannot prevent the fault current contributions from the AC grid and DC customer sides. On the other hand, for a P-to-P fault at location 3, the fault current contribution from upstream is limited by the DC-DC bidirectional converter. 


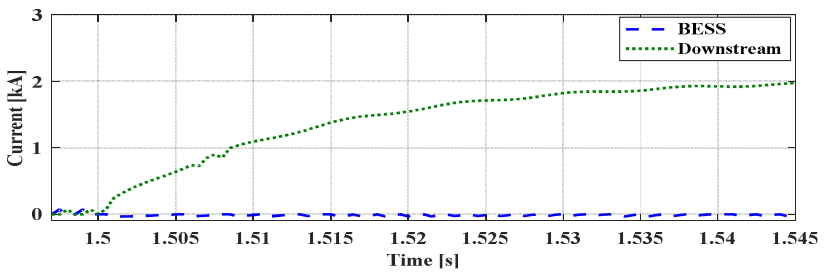

(a)

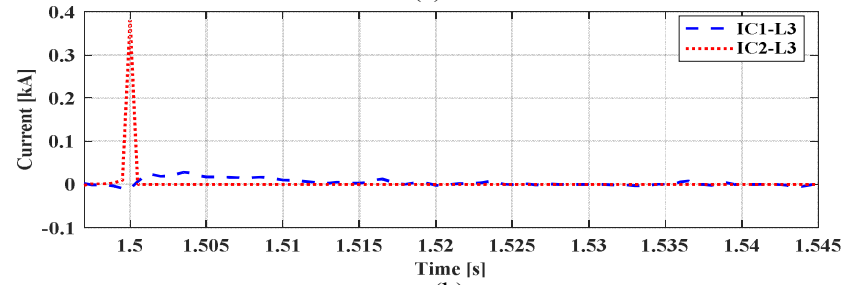

(b)

Fig. 11 Pole-to-earth fault response at location 3, (a)BESS and downstream fault profiles (b) current profiles of the earthing capacitors $\mathrm{C} 1$ and $\mathrm{C} 2$

Table 4 Earthing diodes (D1) and (D2) operation sequence during a different faults for both operation modes

\begin{tabular}{cccc}
\hline Type of Fault & Location 1 & Location 2 & Location 3 \\
\hline \hline \multirow{2}{*}{ Pole-to-Pole } & D1 ON & D1 OFF & D1 OFF \\
& D2 OFF & D2 ON & D2 OFF \\
\hline \multirow{2}{*}{ Pole-to-Earth } & D1 ON & D1 ON & D1 OFF \\
& D2 ON & D2 ON & D2 ON \\
\hline
\end{tabular}

In the condition of a DC pole-to-earth (P-to-E) fault only the transient DC fault current is encountered which is depending on the location of the fault. The capacitors are shorted by their parallel diodes and high transient currents will be circulated between the capacitor and the diode as presented in Table 4

In summary, it has been shown from the study that the fault behaviour of a DC microgrid with multiple converters and multiple earthing points under different fault conditions depends on the fault type and location. The DC microgrid is very sensitive to faults, which can be noticed in this study that different high transients and steady state fault currents are obtained under different operation modes. However, the high current and steady state fault current during islanded operation have shown that it is challenging for protection devices to detect such a fault, as they do not present high enough fault currents to trigger the protection device. With multiple earthing points, both pole to pole and pole to earth faults can demonstrate a high transient fault current during the fault event. Whilst, during pole to earth fault in location 1 and location 2 the diode has provided a short circuit path that leads to the discharge of both capacitor earthing points as illustrated in Table 4.

\section{CONCLUSIONS}

This paper has investigated in detail the fault behaviour of a DC microgrid with multiple earthing points under gridconnected and islanded operation by preforming detailed transient simulations. The simulation results have shown that upstream DC pole-to-pole faults in comparison to the DC pole-to-earth faults can cause high transient fault currents to be discharged in the microgrid, followed by high uncontrolled steady state fault current. The results have also shown significant changes in the DC fault current profiles when the DC microgrid is operated in islanded mode. The total current transient discharge was reduced almost to $1 / 3$ compared to grid-connected mode. This is in addition to the reduction in the steady-state fault currents that can create protection operation challenges for detecting and locating DC fault in islanded DC microgrids. The paper has also demonstrated that multiple earthing using capacitors in parallel with diodes provides different response to different faults and at different locations. The authors will use these features for designing an effective protection scheme which can be used to provide secure protection of DC microgrids in both grid-connected and islanded operation, and the results will be considered in future publications.

\section{ACKNOWLEDGEMENT}

This work has been supported through the EPSRC Centre for Doctoral Training in Future Power Networks and Smart Grids.

\section{REFERENCES}

[1] D. Wang, A. Emhemed, P. Norman, and G. Burt, "Evaluation of Existing DC Protection Solutions on the Performance of an Active LVDC Distribution Network under Different Fault Conditions," Cired 2017, no. June, pp. 12-15, 2017.

[2] T. Dragičević, X. Lu, J. C. Vasquez, and J. M. Guerrero, "DC Microgrids - Part II: A Review of Power Architectures, Applications, and Standardization Issues," IEEE Transactions on Power Electronics, vol. 31, no. 5. pp. 3528-3549, 2016.

[3] IEC, "IEC60050-617-04-22, Area Organization/Market of electricity / Connection and supply," IEC, no. 1.0, 2017.

[4] T. Hakala, P. Virtanen, and T. Kasteenpohja, "Lvdc Rules Towards Industrial-Scale Application of Low-Voltage Direct Current in Public Power Distribution," CIRED Work., no. June, pp. 2-5, 2016.

[5] L. Gao, Y. Liu, H. Ren, and J. Guerrero, "A DC Microgrid Coordinated Control Strategy Based on Integrator CurrentSharing," Energies, vol. 10, no. 8, p. 1116, 2017.

[6] J. M. Guerrero, J. C. Vasquez, J. Matas, L. G. De Vicuña, and M. Castilla, "Hierarchical control of droop-controlled AC and DC microgrids - A general approach toward standardization," IEEE Trans. Ind. Electron., vol. 58, no. 1, pp. 158-172, 2011.

[7] P. Nuutinen et al., "Research Site for Low-Voltage Direct Current Distribution in a Utility - Structure, Functions, and Operation," IEEE Trans. Smart Grid, vol. 5, no. 5, pp. 25742582, 2014.

[8] V. Staudt et al., "Short-circuit protection in DC ship grids based on MMC with full-bridge modules," in Electrical Systems for Aircraft, Railway and Ship Propulsion, ESARS, 2015, vol. 2015May.

[9] D. Wang, A. Emhemed, and G. Burt, "A novel protection scheme for an LVDC distribution network with reduced fault levels," in 2017 IEEE 2nd International Conference on Direct Current Microgrids, ICDCM 2017, 2017, pp. 69-75.

[10] Z. Shuai, "Comparative Study of Short-Circuit Fault Characteristics for VSC-based DC Distribution Networks with Different Distributed Generators," IEEE J. Emerg. Sel. Top. Power Electron., vol. 6777, no. c, pp. 1-12, 2018.

[11] D. Wang, A. Emhemed, G. Burt, and P. Norman, "Fault Characterisations of an Active LVDC Distribution Network for Utility Applications," Upec 2016, pp. 0-5, 2016.

[12] A. Lana, "Control of directly connected energy storage in LVDC distribution network," 11th IET Int. Conf. AC DC Power Transm., vol. 2015, no. CP654, p. 029 (6 .)-029 (6 .), 2015.

[13] R. Gupta, G. "Modeling and design of MPPT controller for a PV module using PSCAD/EMTDC," IEEE PES Innov. Smart Grid Technol. Conf. Eur. ISGT Eur., pp. 1-6, 2010. 